\title{
Brain training with non-action video games enhances aspects of cognition in older adults: a randomized controlled trial
}

\author{
Soledad Ballesteros ${ }^{1 *}$, Antonio Prieto ${ }^{1}$, Julia Mayas ${ }^{1}$, Pilar Toril ${ }^{1}$, Carmen Pita ${ }^{1}$, \\ Laura Ponce de León ${ }^{1}$, José M. Reales ${ }^{1}$ and John Waterworth ${ }^{2}$ \\ 'Studies on Aging and Neurodegenerative Diseases Research Group, Department of Basic Psychology II, Universidad Nacional de Educación a Distancia, Madrid, \\ Spain \\ ${ }^{2}$ Department of Informatics, Umea University, Umea, Sweden
}

Edited by:

Rodrigo Orlando Kuljiš, Zdrav Mozak

Limitada, Chile

Reviewed by:

Francisco Barcelo, University of Illes

Balears, Spain

Dafin F. Muresanu, University of

Medicine and Pharmacy 'Iuliu

Hatieganu', Romania

${ }^{*}$ Correspondence:

Soledad Ballesteros, Department of

Basic Psychology II, Universidad

Nacional de Educación a Distancia,

Juan del Rosal, 10,

28040 Madrid, Spain

e-mail: mballesteros@psi.uned.es
Age-related cognitive and brain declines can result in functional deterioration in many cognitive domains, dependency, and dementia. A major goal of aging research is to investigate methods that help to maintain brain health, cognition, independent living and wellbeing in older adults. This randomized controlled study investigated the effects of 20 1-h non-action video game training sessions with games selected from a commercially available package (Lumosity) on a series of age-declined cognitive functions and subjective wellbeing. Two groups of healthy older adults participated in the study, the experimental group who received the training and the control group who attended three meetings with the research team along the study. Groups were similar at baseline on demographics, vocabulary, global cognition, and depression status. All participants were assessed individually before and after the intervention, or a similar period of time, using neuropsychological tests and laboratory tasks to investigate possible transfer effects. The results showed significant improvements in the trained group, and no variation in the control group, in processing speed (choice reaction time), attention (reduction of distraction and increase of alertness), immediate and delayed visual recognition memory, as well as a trend to improve in Affection and Assertivity, two dimensions of the Wellbeing Scale. Visuospatial working memory (WM) and executive control (shifting strategy) did not improve. Overall, the current results support the idea that training healthy older adults with non-action video games will enhance some cognitive abilities but not others.

Keywords: attention, brain plasticity, cognitive aging, non-action video games, speed of processing, training, wellbeing

\section{INTRODUCTION}

The current computer-based randomized controlled trial was conducted to determine the effects of training with non-action video games on cognitive functioning in healthy older adults. To evaluate possible transfer effects, we assessed a broad variety of cognitive functions that decline with age as well as subjective wellbeing in a pretest-training-post-test randomized controlled trial design with an experimental group and a control group.

Normal aging is associated with age-related gray and white matter shrinkage, with the prefrontal cortex showing greater change than posterior regions. The lateral prefrontal cortex, the cerebellum and the medial temporal lobe system, including the hippocampus, are also affected while minimal or no reduction of volume occurs in entorhinal and the occipital cortices (Raz, 2000; Squire et al., 2004; Raz et al., 2005; see Park and Reuter-Lorenz, 2009). These brain changes are associated with declines in processing speed, executive functions, working memory (WM) and episodic memory (e.g., Salthouse, 1996; Baltes and Lindenberger, 1997; Park and Gutchess, 2002; Nilsson, 2003; Rönnlund et al., 2005; Hoyer and Verhaeghen, 2006). General knowledge, verbal abilities (e.g., Park et al., 2002; see Hedden and Gabrieli, 2004; Craik and Bialystok, 2006), and implicit memory (e.g., Mitchell and Bruss, 2003; Wiggs et al., 2006) are mostly preserved. Even mild cognitively impaired older adults (Ballesteros et al., 2013b) and Alzheimer's disease patients (Ballesteros and Reales, 2004) showed preserved implicit memory despite deteriorations in episodic memory. Interestingly, electrophysiological (Osorio et al., 2010; Sebastián and Ballesteros, 2012) and event-related functional magnetic resonance imaging (Ballesteros et al., 2013a) studies have shown altered neural priming in older adults, despite preserved behavioral priming, suggesting a form of compensation.

Given the increase in life expectancy, and its association with occurrence of neurodegenerative diseases (e.g., Ferri et al., 2005; Brookmeyer et al., 2011; Reitz et al., 2011), identifying factors that might protect elders from cognitive decline is of great importance. Thus, the interest in interventions that can preserve and/or improve cognition in older adults has grown notably in the last decade. Computer-based interventions can easily be used with the elderly and could be a good alternative to traditional training 
programs (Kueider et al., 2012). Thus, researchers are increasingly using new technology tools, including cognitive training platforms and video games, to investigate their impact on cognition (e.g., Thompson and Foth, 2005; Craik et al., 2007; Mozolic et al., 2011; Buitenweg et al., 2012).

A wealth of data supports the view that there is potential for positive changes in older adults (e.g., see Hertzog et al., 2009; Valenzuela and Sachdev, 2009; Park and Bischof, 2013). Neuroplasticity, or the ability of the brain to adapt to environmental change by modifying neural connectivity and brain function (Knaepen et al., 2010), has been shown in animal studies, suggesting experience-induced increases in the hippocampus of those individuals living in an enriched environment (e.g., Kempermann et al., 2002, 2004).

Human studies have shown neural plasticity at several levels of the neural substrate (e.g., Pascual-Leone et al., 2005; Raz et al., 2005) although not to the same degree in old as in young adults (e.g., Bialystok and Craik, 2006; Li et al., 2006; Lee et al., 2008). The aging brain retains some neuroplasticity and the behavior of the individual can influence it (Cacciopo et al., 2006). The prolonged mismatch between functional organismic supplies and environmental demands produces cognitive plasticity and denotes the capacity of the brain for implementing behavioral flexibility (Lövdén et al., 2010; Bavelier et al., 2012). Based on the idea of neuroplasticity, different types of interventions have intended to ameliorate cognitive and functional decline by strengthening social networking (Waterworth et al., 2009; Peter et al., 2013), training cognitive skills (Jones et al., 2006), promoting an active lifestyle (Ballesteros et al., 2013c) or training physical activity (Colcombe et al., 2004; for reviews see Colcombe and Kramer, 2003; Hötting and Röder, 2013).

Training programs have been effective in improving older adults' cognitive performance in memory tasks (e.g., Craik et al., 2007; Smith et al., 2009; Hampstead et al., 2012) and other functions such as attention, working memory, reasoning, speed of processing, cognitive control and dual-task switching (e.g., Edwards et al., 2005; Bherer et al., 2006; Erickson et al., 2007; Berry et al., 2010; Mozolic et al., 2011; Anguera et al., 2013).

Training with video games is a fast-moving industry that claims to improve the cognition of users although the scientific evidence for this is at best mixed. A large-scale cognitive training study conducted by Ball et al. (2002) found that when memory, attention, and problem solving were trained independently, trainees improved in the skill trained but there was no transfer to other untrained skills. However, the main question is whether these benefits transfer to other untrained functions, improving the cognitive functioning of the elders (Lustig et al., 2009; see Buitenweg et al., 2012).

Cognitive training studies suggest that playing action video games enhances a variety of cognitive and perceptual abilities, including peripheral vision and visuospatial attention (e.g., Green and Bavelier, 2003, 2006; Green et al., 2010; Chisholm and Kingstone, 2012), visual short-term memory, switching between tasks, object mental rotation and executive control functions in young and older individuals (e.g., Basak et al., 2008; Boot et al., 2008; Colzato et al., 2010; Cain et al., 2012; Lee et al., 2012; for reviews see Bavelier et al., 2012). In contrast, other studies did not find transfer to cognitive functioning (e.g., Owen et al., 2010; Boot et al., 2013), improvements were very small (e.g., Ackerman et al., 2010), or young but not older adults showed transfer (e.g., Dahlin et al., 2008). For instance, Owen et al. (2010) trained 11,430 participants online for 6 weeks on cognitive tasks designed to improve planning, memory, reasoning, visuospatial abilities, and attention but they found no evidence that training improved cognitive functioning beyond the trained tasks.

Action video game training seems to improve several perceptual and cognitive abilities. However, most action video games are fast, intense, and unpredictable, emphasize peripheral processing, require selection between different action plans and might sometimes be violent (e.g., Green and Bavelier, 2003, 2006; Feng et al., 2007; Chisholm and Kingstone, 2012). These characteristics make this type of games unsuitable for older adults. Action games induced the lowest intervention compliance compared to non-action games. In addition, action games were rated as less enjoyable than non-action games (Nap et al., 2009; see McKay and Maki, 2010; Boot et al., 2013). Fortunately, studies with young (Oei and Petterson, 2013) and older adults (e.g., Cassavaugh and Kramer, 2009; Ackerman et al., 2010; McDougall and House, 2012; Nouchi et al., 2012; Anguera et al., 2013) suggest that cognitive improvements are not limited to action games.

Despite the interest in video games as intervention tools, evidence of their efficiency is at best mixed. However, a recent metaanalytic study (Toril et al., 2014) indicated positive effects that were moderated by variables such as the age of the trainees, the length of the training program, and the cognitive(s) function(s) assessed.

The present study was conducted to evaluate the effects of training older adults with non-action video games, to determine whether the benefits transfer to a broad number of cognitive functions. We trained a group of healthy older adults in the laboratory for 201 -h sessions over the course of 10-12 weeks. In each session, the trainees practiced twice 10 non-action video games. We compared their pre- and post-test results in a series of psychological tests and computerized tasks with those of a non-contact control group to examine possible transfer of training to untrained tasks. The main question was whether the trained older brain would be able to use its plasticity to cope with age-related cognitive declines in several cognitive functions. A second goal was to find out whether the intervention would also improve the subjective wellbeing of the trainees.

\section{MATERIALS AND METHODS}

The current study was approved and conducted in compliance with the guidelines set out by the Universidad Nacional de Educación a Distancia (UNED) Ethical Review Board. The study was conducted between January and July of 2013 in Madrid, Spain. All the participants gave their written informed consent before the study started and were remunerated $75 €$ for their participation. The remuneration was for travel expenses. They were informed of their right to terminate participation in the study at any time. 


\section{PARTICIPANTS}

Sixty participants were recruited through flyers, word of mouth, and local community centers for the elderly. Twenty of these declined to participate. Forty healthy older volunteers (age range 57-80-years-of-age) participated in the study. After signed the informed consent, they were randomly assigned to either the experimental group or the control group before being evaluated on the laboratory tasks. All participants lived active independent lives, with normal hearing and normal or corrected-tonormal vision. All reported being right-handed, and were free of neurological or psychiatric disorders and traumatic brain injury.
The study was completed by 17 of the 20 participants in the video game training group ( 1 dropout suffered an eye operation during training and the other 2 dropouts had availability problems) and by 13 of the 20 participants in the control group ( 1 dropout had a knee operation, 1 had a foot operation, 1 was deceased, 1 was diagnosed with MCI during the course of the study, and 2 were not motivated). Analyses of background characteristics revealed no differences between participants remaining in the study and the dropouts within the respective group, except in the Mini-Mental State Examination and this was due to a control participant diagnosed with MCI during the course of the study (see Figure 1).

\section{CONSORT 2010 Flow Diagram}

\section{Enrollment}

Assessed for eligibility $(n=60)$

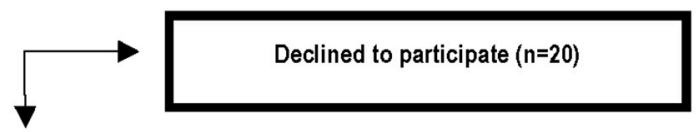

Randomized $(n=40)$

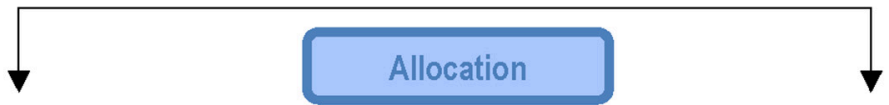

Allocated to intervention: Experimental group ( $n=20)$

Allocated to intervention: Control group $(n=20)$

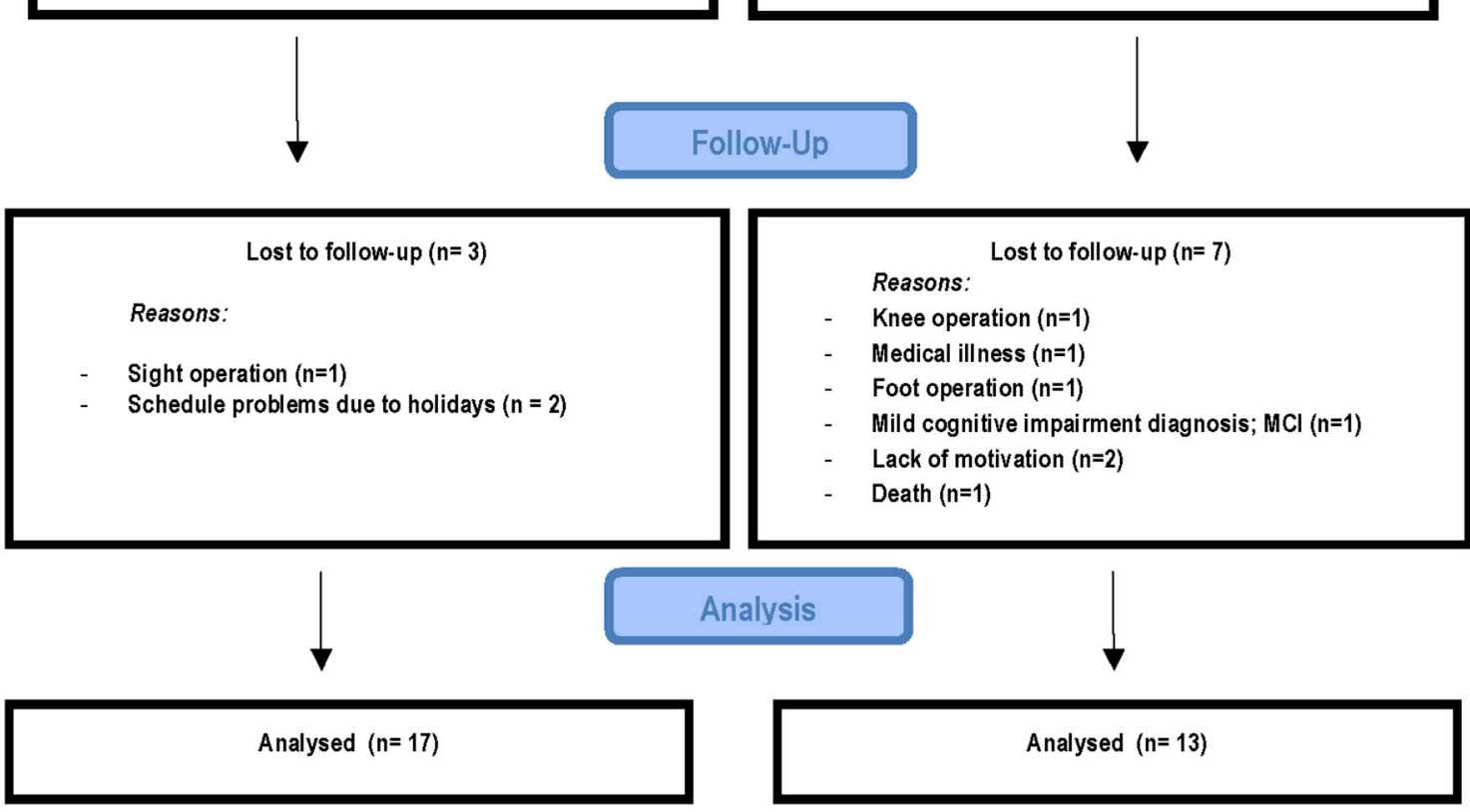

FIGURE 1 | Consort flowchart. 


\section{STUDY DESIGN}

To be included in the study, participants: (1) had to score 26 or above in the MMSE (Folstein et al., 1975); (2) obtain under 5 in the Yesavage Depression Scale (Yesavage et al., 1983; Spanish adaptation by Martínez et al., 2002); and (3) obtain a normal score in the Vocabulary subscale of the WAIS-III scale (Wechsler, 1999). Table 1 summarizes the demographics and screening test scores for each group. T-tests showed no significant differences between the two groups (all $p s>0.05$ ) for all of these measures prior to the intervention.

Transfer of training was measured as performance improvement at post-test relative to pretest. Participants in both groups individually completed a pretest assessment distributed over 2 days (2-h per day). Immediately following the intervention phase, or a similar period in the case of the controls, all participants completed two post-test sessions similar to pretest. Participants in both groups attended the 5 assessment sessions (screening, 2 pre-, and 2 post-test sessions). At pretest (session 1), participants performed a cross-modal oddball task, followed by the spatial WM tasks (Rey-Osterrieth Figure Test, Corsi Blocks and Jigsaw-Puzzle Test). After a rest, they performed the Wisconsin Card Sorting Task (WCST), between two speeded tasks (simple and choice RT tasks) that were counterbalanced across participants. In session 2, participants performed Memory Faces 1 and Wellbeing IPF-IL followed, after a 25 min rest, by Memory Faces II. Then, participants performed Family Pictures I followed, after 25 min by Family Pictures II. The post-test was identical to the pretest.

\section{OVERVIEW OF THE TRAINING PROGRAM}

Participants assigned to the experimental group underwent 20 1-h training sessions over 10-12 weeks. In each session, they practiced twice 10 video games selected from Lumosity (http:// www.lumosity.com), a web-based cognitive training platform that includes games designed with the purpose of improving the user's cognitive abilities (Stemberg et al., 2013). Participants practiced the games in our laboratory on a PC equipped with a 21-inch monitor. Scores on each game were recorded. Below we describe the games briefly. The control group did not receive training but met three times with the researchers in a room of the laboratory. Each meeting lasted about $2 \mathrm{~h}$. During these meetings members of the research group discussed with the participants

Table 1 | Demographic Information for participants in each group.

\begin{tabular}{lccccc}
\hline Characteristic & Experimental & Control & $\boldsymbol{\eta}_{\boldsymbol{p}}^{\mathbf{2}}$ & $\boldsymbol{p}$ & $\boldsymbol{F}$ \\
\hline Women/men (n) & $10 / 7$ & $8 / 5$ & 0.001 & 0.885 & 0.021 \\
Age (years) & $68.8(5.15)$ & $69.2(5.91)$ & 0.001 & 0.849 & 0.037 \\
Education (years) & $12.2(5.09)$ & $12.9(3.28)$ & 0.008 & 0.649 & 0.212 \\
MMSE & $28.7(1.16)$ & $28.8(1.03)$ & 0.001 & 0.847 & 0.038 \\
Depression & $1.5(1.18)$ & $2.4(2.88)$ & 0.035 & 0.320 & 1.023 \\
Verbal ability & $62.4(9.43)$ & $60.8(7.37)$ & 0.017 & 0.495 & 0.479
\end{tabular}

Means and Standard deviations (SDs in parentheses); MMSE, Mini-Mental State Examination; Verbal ability, Vocabulary (Wechsler); Depression, Yesavage Depression Scale. general topics related to aging and their interests. They have coffee and soft drinks together.

\section{Speed mach}

The player was presented with a symbol that appears on the computer screen and had to remember the symbol and compare it with the symbol that appeared immediately before (same, different) by pressing one of two keys as soon as possible.

\section{Memory matrix}

A variable in size matrix appeared at the center of the screen with a pattern of blocks temporarily displayed. The player reported the position of the blocks by clicking on the positions of the matrix where the blocks were presented.

\section{Rotation matrix}

An array of blocks rotated and the player had to rotate mentally the pattern and click on the correct positions.

\section{Face memory}

The player had to decide whether the face that currently appeared on the screen matched the face shown one (1-back), two (2-back), or three (3-back) faces shown before.

\section{Memory match}

Players had to remember each new symbol and compare it with the one shown previously (same, different) by pressing one of two keys as fast as possible.

\section{Money comb}

A money comb appeared at the center of the screen and a sequence of tokens of different values was presented briefly inside it. The task consisted of clicking on the correct tiles to reveal the tokens in the correct order (from lowest to highest value).

\section{Lost in migration}

A static flock of birds appeared at the center of the screen. The goal was to identify the orientation of the bird that appeared at the center by pressing one of the four arrow keys on the keyboard as fast as possible.

\section{Space junk}

After a brief countdown, a series of elements appeared on the screen. The player determined the number of the presented items by pressing the corresponding number on the screen number pad.

\section{Raindrops}

A raindrop containing an equation was falling down from the top of the screen. The gamer had to solve the equation before it reached the water below by pressing the correct number on the number pad.

\section{Chalkboard}

Two boxes with different numbers appeared on the screen. The gamer determined which box contained the larger number by pressing the arrow keys on the keyboard.

Participants received points based on their performance on each video game. In four games (Memory match, Memory faces, 
Speed match, and Lost in migration) the time necessary to complete the game was also recorded. None of the participants in the study informed of having any previous experience with video games.

\section{ASSESSMENT TASKS AND PROCEDURES}

Assessment measures fell into one of six broad domains: processing speed, attention, executive control, spatial working memory, episodic memory, and subjective wellbeing. The computerized tasks (simple and choice reaction time), oddball, Corsi blocks, Jigsaw-puzzles) were programmed using E-Prime 2.0 (Psychology Software Tools Inc, Pittsburg, PA, USA). Executive control was assessed with a computerized version of the Wisconsin Card Sorting Test (WCST). To perform these tasks, participants were comfortably seated at a distance of approximately $55 \mathrm{~cm}$ from the computer screen. These tasks and psychological tests are described below.

\section{SPEED OF PROCESSING (SIMPLE AND CHOICE RT) TASKS}

Task order was counterbalanced across participants. Each task started with a practice block with visual feedback followed by 4 blocks of 40 trials each. In the simple RT task, participants viewed a target that appeared at the center of the computer screen in Times New Roman font (size 20) and pressed a designated key as soon as possible. Each trial consisted of a fixation cross $(1000 \mathrm{~ms})$, followed by a blank screen displayed for 500 or $1000 \mathrm{~ms}$ (randomly selected) after which the target (" $\mathrm{X}$ " in the simple RT task) appeared. In the choice RT task the stimuli were " $\mathrm{X}$ " or " $\mathrm{O}$ " and participants pressed a designated key for each of them. Response keys were counterbalanced across participants. Stimuli disappeared after response or after $5000 \mathrm{~ms}$. The inter-trial interval lasted $750 \mathrm{~ms}$. In 10 percent of the trials, the target was not presented (catch trials) in the detection task. The dependent variable was response time for correct responses. Both tasks lasted approximately 15-20 min and all participants completed a practice session with visual feedback before the start each RT task.

\section{EXECUTIVE CONTROL (WCST)}

Participants performed the WCST (CV4; Heaton, 1981). On each trial, four cards differing in shape (square, triangle, circle or star), color (blue, red, yellow or green) and number of shapes (one, two, three, or four) were displayed on the computer screen. The participant sorted the cards into different categories according to shape $(\mathrm{S})$, color $(\mathrm{C})$, or number of shapes $(\mathrm{N})$. The task consisted on matching a card displayed in the lower right corner of the screen with one of the four cards displayed at the top. Identification of the sorting category was based on feedback from the computer. The sorting criterion changed after 10 consecutive correct trials. Each response card could be matched with a stimulus card on the basis of one or more dimensions. The computer recorded each response as correct or incorrect. The task ended after 10 consecutive responses to each category in the order CSNCSN, or when the two sets of 64 response cards had been presented. The main dependent variable was the number of perseverative errors, which is associated with the shrinking of frontal areas (Gunning-Dixon and Raz, 2003). Patients suffering from prefrontal brain lesion persist in using the same rule (Milner, 1963). The task lasted approximately $30-40 \mathrm{~min}$.

\section{CROSS-MODAL ODDBALL ATTENTION TASK}

We used an in-house developed cross-modal visual-auditory oddball task to assess distraction and alertness. Participants categorized a visual digit from 1 to 8 as odd or even by pressing one of two keys (counterbalanced across participants). There were 3 blocks of 384 trials each. A trial began with the presentation of a fixation cross at the center of the screen as well as a $200 \mathrm{~ms}$ sound. The digit appeared $100 \mathrm{~ms}$ after the sound's offset, and remained on the screen for $200 \mathrm{~ms}$. There were 3 sound conditions: A silent block and two block of trials containing two different sounds, the standard sound (used in $80 \%$ of the trials) that was a $600 \mathrm{~Hz}$ sine wave tone of $200 \mathrm{~ms}$, and the novel sound (the $20 \%$ of the trials; e.g., drill, hammer, rain). Sounds were presented binaurally through headphones at approximately $75 \mathrm{~dB}$ SPL. Results from this task have been reported separately (see Mayas et al., 2014).

\section{VISUOSPATIAL WORKING MEMORY}

Spatial WM (Baddeley and Hitch, 1974), was assessed with the Corsi blocks and the Jigsaw-puzzle tasks. Participants also performed the Rey-Osterrieth Complex Figure Test.

\section{Corsi task}

The original task (Milner, 1971) consisted of a set of nine identical blocks $(3 \times 3 \times 3 \mathrm{~cm})$ unevenly positioned on a wooden board $(23 \times 28 \mathrm{~cm})$. The participant had to point to the blocks in their presentation order. The length of the block sequences increases until recall was no longer correct. We used a computerized version of the task with four difficulty levels (2, 3, 4, and 5 cubes) and 10 trials per level. The stimuli appeared one by one at the computer screen inside a $10 \times 10 \mathrm{~cm}$ matrix for $1000 \mathrm{~ms}$ each. On each trial, the participant reproduced the pattern of cubes just presented. The score was the proportion of correct sequences for each level.

\section{The Jigsaw-puzzle task}

The pencil and paper task was developed to assess active visuospatial abilities (Richardson and Vecchi, 2002). In our computerized version, the puzzles consisting of 4, 6, or 9 pieces were presented at the computer screen. Each piece was numbered and the participant had to write down the number corresponding to the pieces in the correct spatial positions. To our knowledge, this is the first computerized version of the task. The stimuli were 15 pictures (e.g., kettle, lamp, chair) with similar visual complexity selected from Snodgrass and Vanderwart (1980). Each picture was fragmented into four, six and nine pieces to produce 45 different puzzles. The pictures were enlarged to fit an area $12 \times 12 \mathrm{~cm}$ and divided into four pieces of $6 \times 6 \mathrm{~cm}$, six pieces of $6 \times 4 \mathrm{~cm}$, or nine pieces of $3 \times 3 \mathrm{~cm}$. Three different counterbalanced orders were generated. Different pictures were used at pre and posttesting. Participants viewed 15 puzzles representing all possible combinations of visual complexity and number of pieces. The response sheets contained grids of the same size as the original pictures with the appropriate number of squares $(4,6,9$, squares). We used 2 puzzles as practice and their results were not included in the analysis. In each trial, a fragmented picture appeared on the screen and the participant wrote down in the response sheet the 
appropriate numbers to form a spatially correct picture. The jigsaw was presented on the computer screen for $90 \mathrm{~s}$. Participants were allowed to correct errors within this time. The proportion of correct puzzles per level (4, 6, and 9 pieces) was the dependent variable.

\section{REY-OSTERRIETH COMPLEX FIGURE TEST}

We used the Spanish adaptation of the test (Rey, 1942, 1999) to assess visual constructive abilities and visuospatial memory. Participants reproduced a complex drawing, first by copying it and then by reproducing the drawing from memory.

\section{IMMEDIATE AND DELAYED VISUAL EPISODIC MEMORY}

Immediate recognition memory for Faces and Family Pictures were assessed with Faces I, and Family Pictures I, while delayed memory (25 min after encoding) was assessed with Faces II and Family Pictures II, from the Spanish version (Wechsler and Pereña, 2004) of the Memory Wechsler Scale, WMS-III (Wechsler, 1997).

\section{WELLBEING}

We assessed wellbeing with the 15-item short version of the SPF-IL Scale (Nieboer et al., 2005) which assesses five wellbeing dimensions. Subjective wellbeing is the overall state of wellbeing of a person determined by his/her ability to obtain the goals of physical and social wellbeing. The maximum score per dimension was 12. The Affection dimension relates to the degree of confidence and social acceptance and their level of satisfaction with the people around them. Assertivity refers to the self-perception to have done the right thing in the eyes of relevant others. Status assesses the feeling of being treated with respect, self-realization, achievement as compared to others, and reputation. Comfort is the absence of feelings of discomfort, pain or stress. Finally, Stimulation refers to mental and physical activation.

\section{RESULTS}

The main question examined was whether training with nonaction video games enhanced cognition of older adults and if training would transfer to other untrained broader cognitive functions. The question was tested by considering whether group (control group, video game trained group) interacted with testing session (pre, post-testing) with regard to performance on a series of cognitive measures.

\section{VIDEO GAME PERFORMANCE}

Video game performance showed significant improvements across sessions. The mean performance on each game was compared at the beginning and the end of training using regression analysis with Training Session as the predictor variable and Reaction Time and Game Score as the criterion variables. The results showed that performance in all games improved significantly after training. $R^{2}$ coefficients were high and accounted for more than $80 \%$ of the variance of the model in all games except Memory Matrix, Money Comb, and Space Junk. The ANOVAs for the previous analyses indicated that all $R^{2}$ coefficients were significant, so Training Session was a reliable predictor of Score and RT in all games. Table 2 presents a summary of the results
Table 2 | Determination coefficients $\left(R^{2}\right), F$ and $p$-values for the 10 trained video games.

\begin{tabular}{lllr}
\hline Video game & DV & $\boldsymbol{R}^{2}$ (corr.) & \multicolumn{1}{c}{$\boldsymbol{F ( \boldsymbol { p } )}$} \\
\hline Speed match & Score & $0.961(0.959)$ & $441.77(0.000)$ \\
& $\mathrm{RT}$ & $0.965(0.963)$ & $492.66(0.000)$ \\
Memory matrix & Score & $0.698(0.681)$ & $38.60(0.000)$ \\
Rotation matrix & Score & $0.884(0.878)$ & $137.32(0.000)$ \\
Money comb & Score & $0.601(0.579)$ & $27.15(0.000)$ \\
Face memory & Score & $0.972(0.971)$ & $626.61(0.000)$ \\
& RT & $0.977(0.976)$ & $719.10(0.000)$ \\
Memory match & Score & $0.852(0.844)$ & $103.81(0.000)$ \\
& RT & $0.960(0.958)$ & $430.21(0.000)$ \\
Lost in migration & Score & $0.964(0.962)$ & $484.67(0.000)$ \\
Space junk & RT & $0.965(0.963)$ & $500.39(0.000)$ \\
Raindrops & Score & $0.485(0.457)$ & $16.97(0.001)$ \\
Chalkboard challenge & Score & $0.893(0.887)$ & $150.88(0.000)$ \\
\hline
\end{tabular}

$D V$, (dependent variable); $R^{2}$ (Regression coefficient); corr. (corrected regression coefficient); $F$ (F-values of ANOVAs); $p$ (significance).

and Figure 2 shows the improvements in each video game as a function of training session in $\mathrm{Z}$ scores.

\section{EFFECTS OF THE INTERVENTION PROGRAM ON COGNITIVE PERFORMANCE}

Next, we explored whether training led to enhancements of cognitive abilities that deteriorate with age. We conducted analyses of variance (ANOVAs) with group (experimental, control) and session (pre, post-testing) as independent variables. Group was inter-subjects while Session was considered as repeated intrasubjects. Analyses were conducted using the SPSS (Version 21).

\section{SIMPLE AND CHOICE RT TASKS}

Mean results and standard deviations are displayed in Table 3. Incorrect trials (less than 1\% for both groups) and those with RTs faster than $200 \mathrm{~ms}$ or slower than $1500 \mathrm{~ms}(0.7$ and $1.19 \%$ for experimental and control group, respectively) were excluded from RT analyses.

A 2 group (experimental, control) $\times 2$ session (pretest, posttest) $\times 2$ task (detection, choice) mixed ANOVA was conducted on mean RTs. The main effect of task was statistically significant $\left[F_{(1,28)}=144.11, M S E=2440.89, p<0.001, \eta_{p}^{2}=0.83\right]$. Participants performed faster on the detection task ( $468 \mathrm{~ms})$ than the choice RT task (578 ms). No other main effect was significant $(p s>0.05)$. However, the three-way interaction group $\times$ session $\times$ task was statistically significant $\left[F_{(1,28)}=3.24\right.$, MSE $=$ 1812.22, $\left.p=0.057, \eta_{p}^{2}=0.12\right]$. The interaction showed that groups did not differ at pre and post-training in the detection task (460 and $483 \mathrm{~ms}$ for the experimental group; 466 and 464 for the control group in pre and post-test, respectively). However, in the choice RT task, the experimental group improved performance after training (566 and $496 \mathrm{~ms}$ for pre and post-session, respectively) while the control group did not (570 and $578 \mathrm{~ms}$ for pre and post, respectively; see Figure 3 ). 
A

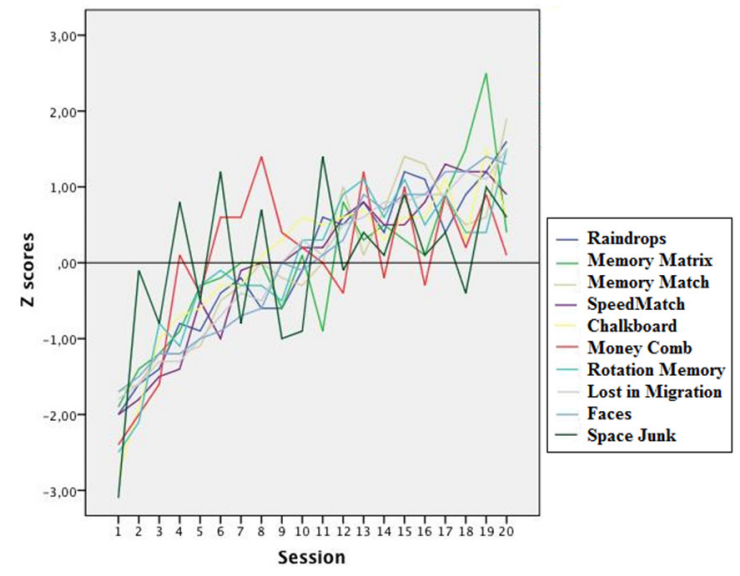

$\mathbf{B}$

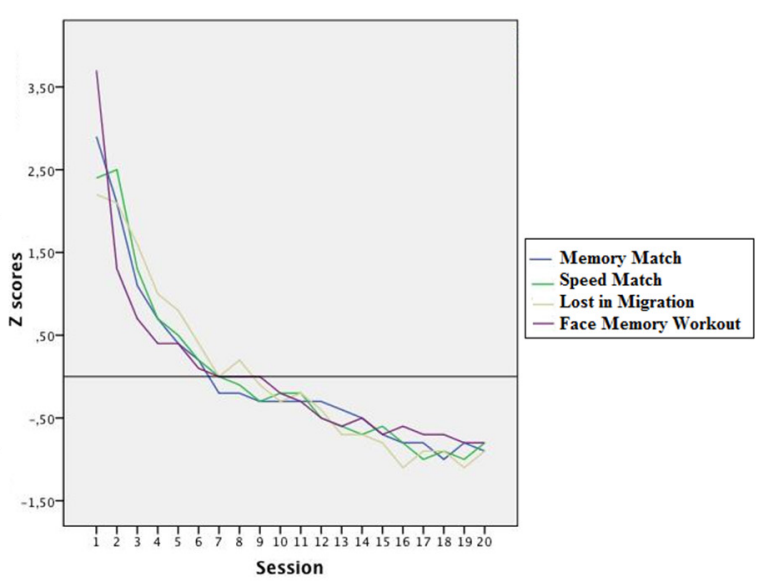

FIGURE 2 | (A) Average performance scores obtained in each of the 10 non-action video games across the 20 training sessions in Z scores (mean 0 ; standard deviation 1). (B) Average response times of 4 video games across the 20 training sessions in $Z$ scores.

\section{EXECUTIVE FUNCTIONS (WCST)}

Table 3 shows the main dependent variables of WCST for both groups at pre and post-tests. Separate mixed ANOVAs with group and session were conducted with percentage of errors, percentage of perseverative responses, percentage of perseverative errors, percentage of non-perseverative errors and percentage of conceptual level errors. The main variable of interest was the proportion of perseverative errors; that is, the total number of errors that occur when the participant is required to switch to another sorting rule but instead, the participant persists in sorting using the rule that was previously correct, relative to the number of trials administered multiplied by 100 .

A group $x$ session mixed ANOVA was performed with the percentage of perseverative errors as the dependent variable. Neither the main effect of group $\left[F_{(1,28)}=0.02, M S E=\right.$ $\left.150.26, p>0.05, \eta_{p}^{2}=0.001\right]$ or session $\left[F_{(1,28)}=1.59\right.$, MSE $=$ $\left.26.85, p>0.05, \eta_{p}^{2}=0.05\right]$, nor the interaction group x session were significant $\left(F_{(1,28)}=0.91, M S E=26.85, p>0.05 ; \eta_{p}^{2}=\right.$ 0.03 ; see Table 2). The same pattern of results was obtained in the ANOVAs conducted in the other dependent measures (all ps $>0.05)$.

\section{CROSS-MODAL ODDBALL ATTENTION TASK}

Accuracy levels in the digit categorization task pre-post in both groups were similar $\left[F_{(1,25)}=1.38, M S E=0.05, p>0.05, \eta_{p}^{2}=\right.$ $0.05]$. Mean accuracy was 0.90 and 0.92 at pre-post for the experimental group, and 0.90 and 0.90 at pre-post for the control group. The main effect of condition was significant $\left[F_{(2,50)}=\right.$ 5.52, MSE $\left.=0.001, p<0.005, \eta_{p}^{2}=0.18\right]$, showing lower correct responses in the novel compared to the silent and the standard conditions $\left[F_{(1,25)}=7.087, M S E=0.001, p<0.05\right.$, and $F_{(1,25)}=5.99, M S E=0.0005, p<0.05$, respectively] while the standard and silent conditions did not differ from each other $(p=0.150)$. The effect of session was not significant $\left[F_{(1,25)}=\right.$ $\left.2.25, M S E=0.0025, p<0.15, \eta_{p}^{2}=0.08\right]$. None of the twoway interactions were significant (all $p s>0.05$ ). The ANOVA performed on correct response times after removing outliers with group and session as between-subjects and condition (silence, standard and novel) as the within-subjects factor, revealed that group was not statistically significant $\left[F_{(1,25)}=1.2, M S E=\right.$ 40075.19, $p=0.27)$ but the main effect of condition was significant $\left[F_{(2,50)}=26.63, M S E=657.99, p<0.001, \eta_{p}^{2}=0.51\right]$. The mean RT corresponding to the standard condition was the fastest $(613 \mathrm{~ms})$, while the slowest was the RT corresponding to the novel condition $(649 \mathrm{~ms})$. The main effect of session was not significant $(p>0.05)$. However, the triple interaction group $\times$ session $\times$ condition was statistically significant $\left[F_{(2,50)}=4.37\right.$, $\left.M S E=403.54, p<0.05 ; \eta_{p}^{2}=0.51\right]$. New analyses were conducted on distraction (novel vs. standard sound) and alertness (silence vs. standard sound), showing that the ability to ignore relevant sounds (distraction) improved significantly in the experimental group after training ( $12 \mathrm{~ms})$ but not in the control group. The analyses of alertness showed that the experimental group increased $26 \mathrm{~ms}$ in alertness $(p<0.05)$ but control group did $\operatorname{not}(p=0.54)$.

\section{SPATIAL WORKING MEMORY (WM) Corsi blocks}

A group (2) $\times$ session (2) x number of blocks (4: 2, 3, 4, and 5 blocks) mixed ANOVA with group as the between-subject factor and time and number of blocks as the within-subject factors was performed on the proportion of correct sequences [number of correct sequences per level/number of sequences per level]. Group and session were not significant (all $p s>0.05$ ) but number of blocks was significant $\left[F_{(1,28)}=237.415, M S E=4.98, p<\right.$ $\left.0.001, \eta_{p}^{2}=0.89\right]$. Performance deteriorated with the increase of the number of blocks. The interaction group $\mathrm{x}$ number was significant $\left[F_{(1,28)}=4.35, M S E=0.09, p<0.001, \eta_{p}^{2}=0.89\right]$, suggesting better performance of the experimental group in the level 4 of the Corsi task $(p=0.013)$ and no difference in the other block conditions. Moreover, the triple interaction group $\times$ session $\times$ number was statistically significant $\left[F_{(1,28)}=3.98\right.$, 
Table 3 | Pre and post-training performance on psychological measures and wellbeing dimensions for the experimental and control groups.

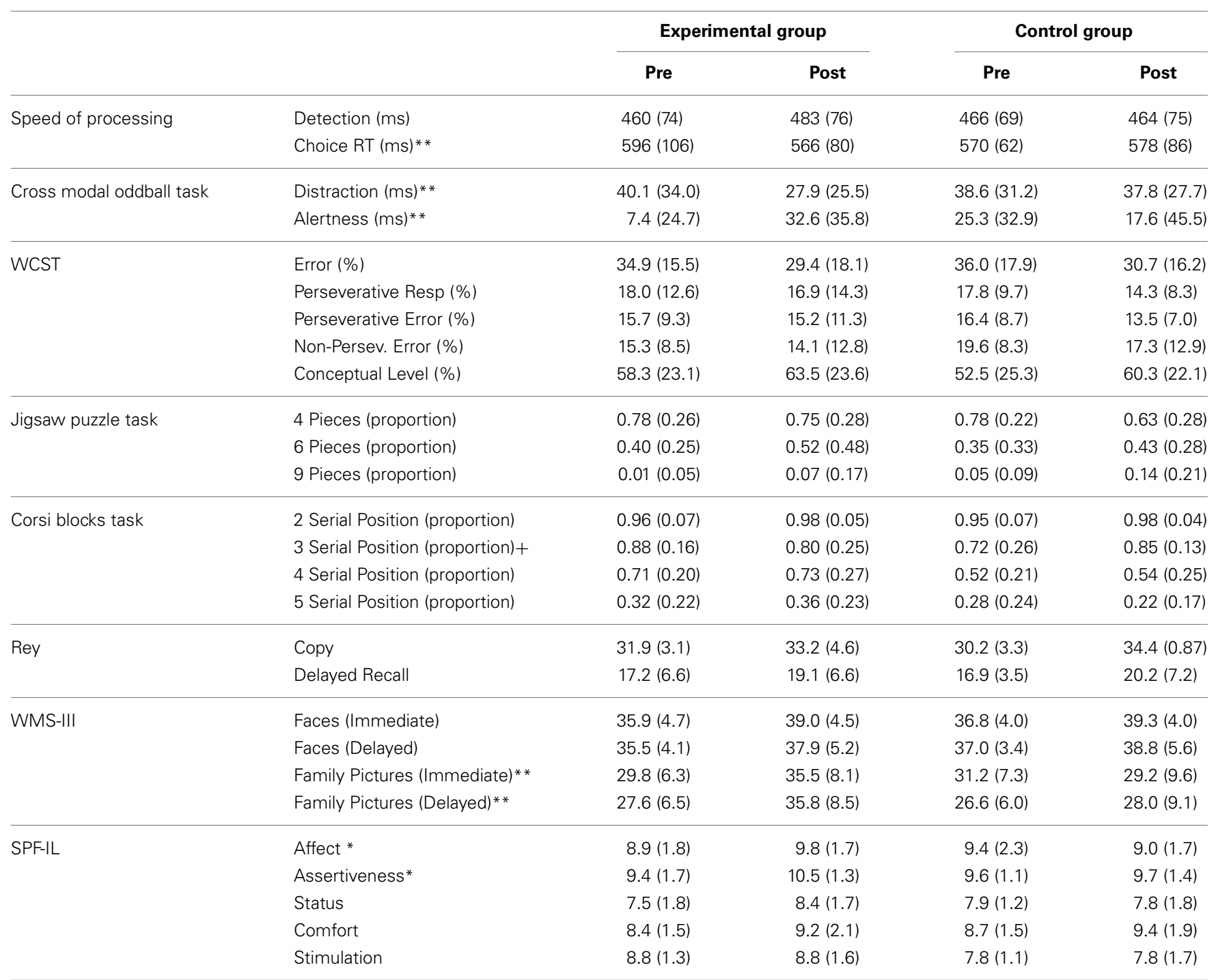

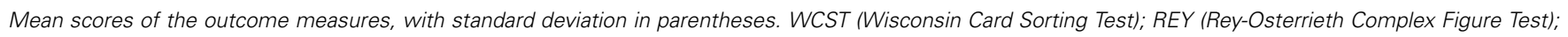

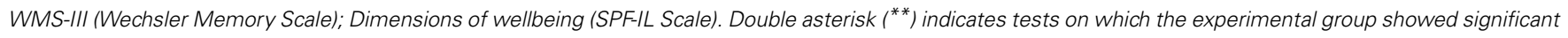

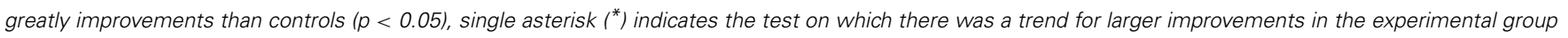
$(p<0.10)$, and the cross $(+)$ indicates the test on which control group showed significantly greater improvements than the experimental group ( $<<0.05)$.

$\left.M S E=0.06, p<0.01, \eta_{p}^{2}=0.12\right]$. The interaction was due to a different pattern of performance between groups with 3 blocks. While the experimental group performed worse at post-test than pretest, an opposite pattern was found in the control group $(p<0.05)$. No other effect was significant.

\section{Jigsaw-puzzle task}

The ANOVA conducted with group, session, and level $(4,6$, and 9 pieces) showed that group and session were not statistically significant $(p s>0.05)$ but level was $\left[F_{(1,28)}=121.352\right.$, $\left.M S E=6.61, p<0.001, \eta_{p}^{2}=0.89\right]$. Performance decreased as the number of pieces increased from 4 to 9 pieces. The interaction session $\mathrm{x}$ level was significant $\left[F_{(1,28)}=3.40, M S E=\right.$ $\left.0.15, p=0.04, \eta_{p}^{2}=0.10\right]$, suggesting that participants performed better at post-test with jigsaws of 6 (0.40 and 0.48) and
9 pieces (0.02 and 0.10) and did not differ with jigsaws of 4 pieces.

\section{VISUAL EPISODIC MEMORY \\ Faces}

A mixed ANOVA group $\mathrm{x}$ session $\mathrm{x}$ delay (immediate, delayed) was performed on the recognition scores. The analysis showed a significant effect of session $\left[F_{(1,28)}=17.98, M S E=176.74, p<\right.$ $\left.0.001, \eta_{p}^{2}=0.39\right]$. The recognition score was significantly higher at post-test $($ mean $=38.76)$ than at pretest $($ mean $=36.31$ and $S D=3.76$ ). No other main factor or interaction was significant.

\section{Family pictures}

The group $\times$ session $\times$ delay mixed ANOVA showed a significant main effect of session $\left[F_{(1,28)}=4.64, M S E=333.73\right.$, 
A

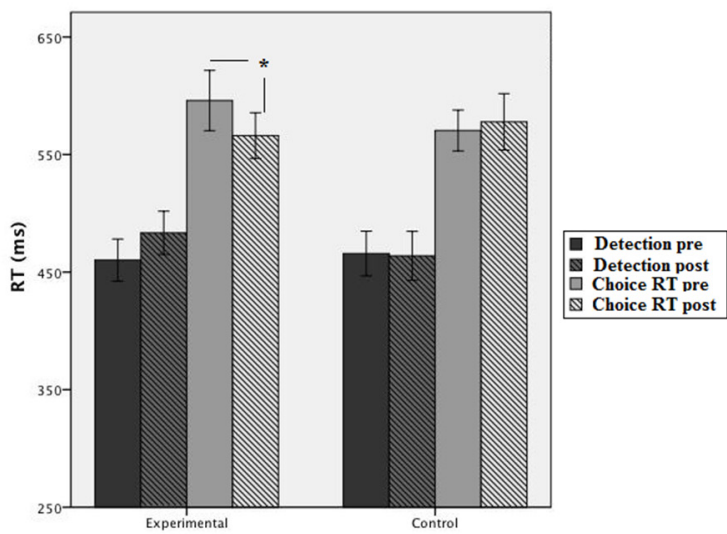

C

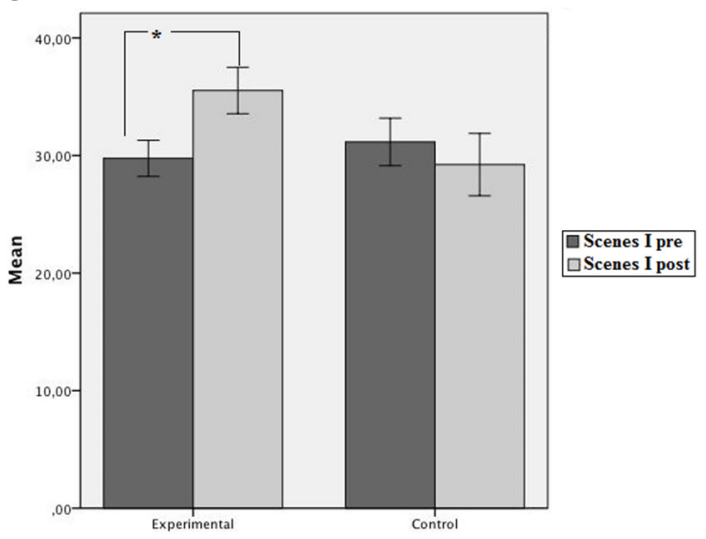

FIGURE 3 | Mean performance of trained and control groups at pretest and post-test. (A) Simple and choice RT tasks. (B)

Distraction and alertness effects in the Cross-modal oddball attention

$\left.p<0.05, \eta_{p}^{2}=0.14\right]$ and delay $\left[F_{(1,28)}=22.78, M S E=107.82\right.$, $\left.p<0.001, \eta_{p}^{2}=0.45\right]$. The interaction group $\times$ session was significant $\left[F_{(1,28)}=5.41, M S E=389.27, p<0.05, \eta_{p}^{2}=0.16\right]$. Groups did not differ at pretest but at post-test the experimental group showed better performance compared to pretest (35.65 vs. 28.68 ) while the control group did not improve (28.62 vs. 28.86). The interactions group $\mathrm{x}$ delay $\left[F_{(1,28)}=5.88, M S E=27.82\right.$, $\left.p<0.05, \eta_{p}^{2}=0.174\right]$ and session $\times$ delay were significant $\left[F_{(1,28)}=13.02, M S E=61.49, p<0.01, \eta_{p}^{2}=0.32\right]$. As these interactions did not include the group factor, they are not discussed further.

\section{WELLBEING}

A $2 \times 2$ mixed repeated measures ANOVA was conducted for results on each of the 5 subscales of the SPF-IL, with group as the between-subjects factor and session as the withinsubjects factor. The results showed a main effect of session in Assertiveness $\left[F_{(1,28)}=4.41, M S E=5.26, p<0.05, \eta^{2}=\right.$ $0.14)$ and Comfort $\left[F_{(1,28)}=5.08, M S E=8.46, p<0.05, \eta^{2}=\right.$ 0.15 ] subscales, due to a general increase in scores at post-test. Group reached statistical significance in the Stimulation subscale
B

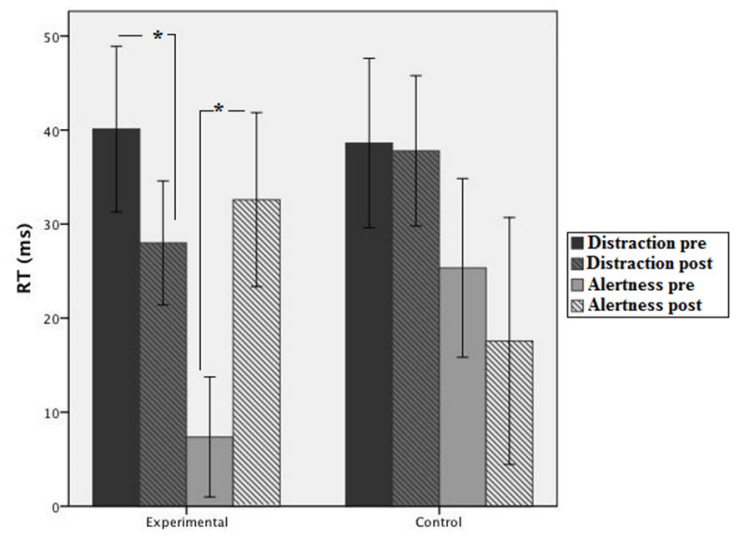

D

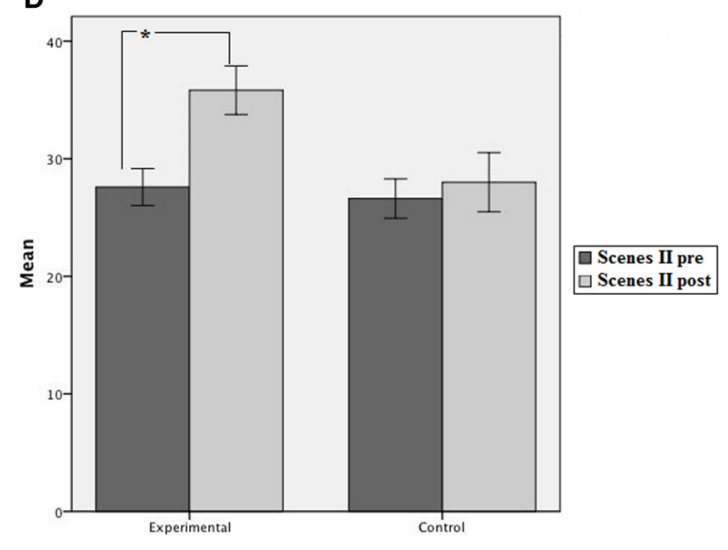

task. (C) Family pictures (Scenes) inmediate. (D) Family pictures (Scenes) delayed. Error bars represent plus and minus 1 standard error. ${ }^{*} p<0.05$.

$\left[F_{(1,28)}=5.58, M S E=13.24, p<0.05, \eta^{2}=0.17\right]$, indicating higher scores in the experimental relative to the control group. The interaction group $\times$ session was marginally significant for Affection $\left[F_{(1,28)}=3.42, M S E=6.47, p=0.07, \eta^{2}=0.11\right]$ and Assertiveness $\left[F_{(1,28)}=3.35, M S E=3.99, p=0.08, \eta^{2}=0.11\right]$ subscales. Planned comparisons showed that the trend was due to the improvement of the experimental group after training suggesting that the trained group improved (marginally) in these dimensions after training while the control group did not.

\section{DISCUSSION}

The results confirmed that the trainees improved significantly in the practiced games (e.g., Ackerman et al., 2010; Reddick et al., 2013). This study yielded two main findings. First, the results indicated that the trained group showed enhancements compared to control participants in: (a) controlled processing, as shown by the significant improvement in the choice RT task; (b) attention, as the trainees were less distracted by irrelevant sounds and showed an increase in alertness; (c) immediate and delayed recall memory for family pictures (WMS-III); and (d) Affection and Assertiveness subscales of the Wellbeing scale. Given the 
age-related declines in these functions, the results seem encouraging. Second, our trained participants neither showed transfer to executive control assessed with the WCST nor to spatial WM assessed with three different tasks.

\section{NON-ACTION VIDEO GAME TRAINING TRANSFERRED TO COGNITION AND WELLBEING}

The enhancement found in processing speed agreed with previous results (e.g., Drew and Waters, 1986; Clark et al., 1987; Maillot et al., 2012). This result has implications for applied aging science, as processing speed is a robust predictor of age-related cognitive decline (e.g., Salthouse, 1996; Zimprich, 2002; Salthouse and Ferrer-Caja, 2003; Eckert, 2011). Speed of processing training is an indicator of efficient performance of daily living activities and safer driving performance (e.g., Ball et al., 2007; Wolinsky et al., 2013).

We also found that the trainees reduced distractibility by improving alertness and attention filtering, functions that decline with age and largely depend on frontal regions (Mayas et al., 2014). A marginal improvement after training was observed in Affection and Assertiveness, two dimensions of subjective wellbeing. The first relates to the degree of confidence and social acceptance and their level of satisfaction with the people around them while the second indicates the self-perception of doing good things, be a good person, and contribute to a common goal. Other studies found no significant changes after training either on selfreported mood and mental health state (Mozolic et al., 2011) or in real-world outcomes (Willis et al., 2006).

\section{TRAINING DID NOT ENHANCE EXECUTIVE CONTROL AND SPATIAL WM}

The frontal lobe hypothesis assumes that age-related cognitive declines are the results of changes that occur in the frontal lobes (West, 1996; Raz, 2000). Older adults are less efficient in inhibitory functioning than younger adults (see Hasher et al., 1999; Andrés et al., 2006). The executive functioning comprises several cognitive abilities including resistance to interference, memory updating, and shifting (Miyake et al., 2000) and decline with age (Kray and Lindenberger, 2000). Larger age-related declines in all WCST indexes were found in MCI older adults compared to healthy elders (Ballesteros et al., 2013b) while a long-term physically active lifestyle improved older adults' performance on the WCST compared to sedentary older adults (Ballesteros et al., 2013c).

Our results did not agree with those of Basak et al. (2008) who found improvements in executive control after training older adults with a video game that combines the speed of realtime gaming with the complexity of strategy-based video games. Possibly, to improve task shifting, it would be necessary to train with strategy-based video games. However, Boot et al. (2013) trained a group with an action game (Mario Kart DS) and other group with a non-action game (Brain Age 2) and did not found any improvement.

Our findings agree with two recent meta-analyses conducted with older adults (Toril et al., 2014) and with trainees from all ages (Powers et al., 2013). Both studies found negligible effects of video game training on executive functions. Only first-person shooter action games studies have reported benefits after training
(Green and Bavelier, 2003, 2006). These types of games require great perceptual abilities and a large emphasis on peripheral visual processing (Green et al., 2010). However, older adults do not like this type of games (Nap et al., 2009; see Boot et al., 2013). Our results contrast with those of Nouchi et al. (2012) who found improvements on executive functions after training older adults with Brain Age 2 after just 5 h of training and Maillot et al. (2012) with exergames training.

The ineffectiveness of training despite the fact that several of the non-action video games mimic WM tasks agreed with findings from two recent reviews (Shipstead et al., 2012; Melby-Lervåg and Hulme, 2013). Importantly, a recent randomized, placebocontrolled study with young adults who received 20 sessions of practice on an adaptive computerized $n$-back training program found no evidence of improvement in multiple measures of verbal and spatial fluid intelligence, multitasking, or WM capacity (Reddick et al., 2013). Boot et al. (2013) reported similar results in Corsi blocks.

\section{CONCLUSIONS, LIMITATIONS AND FUTURE DIRECTIONS}

Animal (e.g., Chen and Tonegawa, 1997; Holtmaat and Svoboda, 2009) and human studies (e.g., Colcombe et al., 2004; PascualLeone et al., 2005; Lindenberger et al., 2006; Anguera et al., 2013) have shown that the adult brain maintains some plasticity, which allows behavior modification through practice. Cognitive training programs based on repetitive practice on cognitive processes have been effective in improving the trained process but not so much other untrained cognitive functions (e.g., Mahncke et al., 2006; Ball et al., 2007; Mozolic et al., 2011; Hampstead et al., 2012).

Our results revealed a causal effect of game training on the cognitive enhancement of healthy elders. Boot et al. (2013) found that neither a group of elders trained with an action video game, nor another trained with a non-action game improved on any cognitive ability compared to a control group. It is possible that the negative results were due to the long training regime $(50 \mathrm{~h}$ vs. 10 to $20 \mathrm{~h}$ in other studies) as the effects are greater when training is of short duration (1-6 weeks) than when it is long (7-12 weeks) in old people (Toril et al., 2014). This finding has practical implications as many intervention programs spend a great amount of time training older participants, on the assumption that longer training will produce better results.

The current study had relatively small sample sizes as have other recent randomized training studies (e.g., Mozolic et al., 2011; Hampstead et al., 2012; Nouchi et al., 2012). Despite the relative small sample used in the present study, we found that participants that completed the 20 training sessions were faster on a choice RT task, showed reduced distraction and an increase in alertness on an oddball attention task, improved memory for visual stimuli and improved (marginally) in two dimensions of wellbeing. These results suggest that the brain of the elderly retains certain neurocognitive plasticity. Whether similar changes in these cognitive functions after training with video games might be observed in young adults, who are at the peak of cognitive functioning, is an important and open question that would deserve further investigation.

It would also be important to demonstrate in future studies maintenance of gains in speed of processing, attention, immediate 
as well as delayed visual recognition memory and variables of wellbeing using long follow-up periods. Future analyses should inform whether cognitive and wellbeing gains are maintained over time after finishing the training program. Our study presents other limitations. One is that it does not examine whether the effect of training may generalize to everyday life tasks. Future studies should investigate whether the improvements found would transfer to real world tasks. Another limitation is related to the difficulty to rule out possible effects due to motivational factors, the familiarity or confidence with the researchers rather than neurocognitive plasticity as the trained group had more contact with the experimenter than the control group. Hence another possible avenue for research will be to include two types of control groups, an active control group and a no-contact control group. However, it should be mentioned that in a recent meta-analytic study (Toril et al., 2014), we have analyzed the effect sizes of those published studies that used both an active and a passive control group (excluding those studies that had just a passive control or no control group). The difference between active and passive control was not statistically significant but they were significantly different from zero. Recognizing these limitations, this study is a controlled first step to show the usefulness of training older adults with non-action video games that seem more appropriate for older adults than other genres of video games.

In sum, video game training might be a promising way to improve certain aspects of cognition that decline with age. It will be important for future studies to demonstrate these positive effects with larger sample sizes. Further studies should investigate whether MCI older adults benefited from training with non-action video games as much as healthy older adults. (MCI) benefited from training with video games as much as healthy older adults.

\section{AUTHOR NOTE}

The authors would like to inform that they have not had any contact with the package manufacturers of the Lumosity cognitive training platform at any time during the duration of the study. This study was conducted independently from them.

\section{ACKNOWLEDGMENTS}

This work was supported by grants from the European Community Ambient Assisted Living Joint Programme (AAL2008-1-014, AGNES), the Spanish Government (PSI2010-21609C2-01) and Madrid Community Biomedical Research grant (S2010/BMD-2349). The authors thank all the older volunteers that participate in the study. The funders had no role in study design, data collection and analysis, decision to publish, or preparation of the manuscript.

\section{REFERENCES}

Ackerman, P. L., Kanfer, R., and Calderwood, C. (2010). Use it or lose it? Wii brain exercise practice and reading for domain knowledge. Psychol. Aging 25, 753-766. doi: 10.1037/a0019277

Andrés, P., Parmentier, F. B. R., and Escera, C. (2006). The effect of age on involuntary capture of attention by irrelevant sounds: a test of the frontal hypothesis of aging. Neuropsychologia 44, 2564-2568. doi: 10.1016/j.neuropsychologia.2006.05.005
Anguera, J. A., Boccanfuso, J., Rintoul, J. L., Al-Hashimi, O., Faraji, F., Janowich, J., et al. (2013). Video game training enhances cognitive control in older adults. Nature 501, 97-101. doi: 10.1038/nature12486

Baddeley, A. D., and Hitch, G. (1974). "Working memory," in The Psychology of Learning and Motivation, ed G. H. Bower (New York, NY: Academic Press), 47-89.

Ball, K., Berch, D. B., Helmer, K. F., Jobe, J. B., Leveck, M. D., Marsiske, M., et al. (2002). Effects of cognitive training interventions with older adults: a randomized controlled trial. JAMA 288, 2271-2281. doi: 10.1001/jama.288.18.2271

Ball, K., Edwards, J. D., and Ross, L. A. (2007). The impact of speed of processing training on cognitive and everyday functions. J. Geront. B Psychol. Sci. Soc. Sci. 62, 19-31. doi: 10.1093/geronb/62.special_issue_1.19

Ballesteros, S., Bischof, G. N., Goh, J. O., and Park, D. C. (2013a). Neural correlates of conceptual object priming in young and older adults: an event-related fMRI study. Neurobiol. Aging 34, 1254-1264. doi: 10.1016/j.neurobiolaging.2012.09.019

Ballesteros, S., Mayas, J., and Reales, J. M. (2013b). Cognitive function in normal aging and in older adults with mild cognitive impairment. Psicothema 25, 18-24. doi: $10.7334 /$ psicothema2012.181

Ballesteros, S., Mayas, J., and Reales, J. M. (2013c). Effects of a long-term physically active lifestyle on cognitive functioning in older adults. Curr. Aging Sci. 6, 189-198. doi: 10.2174/18746098112059990001

Ballesteros, S., and Reales, J. M. (2004). Intact haptic priming in normal aging and Alzheimer's disease: evidence for dissociable memory systems. Neuropsychologia 44, 1063-1070. doi: 10.1016/j.neuropsychologia.2003.12.008

Baltes, P. B., and Lindenberger, U. (1997). Emergence of a powerful connection between sensory and cognitive functions across the adult life span: a new window to the study of cognitive aging? Psychol. Aging 12, 12-21. doi: 10.1037//0882-7974.12.1.12

Basak, C., Boot, W. R., Voss, M. W., and Kramer, A. F. (2008). Can training in realtime strategy video game attenuate cognitive decline in older adults? Psychol. Aging 23, 765-777. doi: 10.1037/a0013494

Bavelier, D., Green, C. S., Pouget, A., and Schacter, P. (2012). Brain plasticity through the lifespan: learning to learn and action video games. Annu. Rev. Neurosci. 35, 391-416. doi: 10.1146/annurev-neuro-060909-152832

Berry, A. S., Zanto, T. P., Clapp, W. C., Hardy, J. L., Delahunt, P. B., Mhancke, H. W., et al. (2010). The influence of perceptual training on working memory in older adults. PLoS ONE 5:e11537. doi: 10.1371/journal.pone.110537

Bherer, L., Kramer, A. F., Peterson, M. S., Colcombe, S., Erickson, K., and Becic, E. (2006). Testing the limits of cognitive plasticity in older adults: application to attentional control. Acta Psychol. 123, 261-278. doi: 10.1016/j.actpsy.2006.01.005

Bialystok, E., and Craik, F. I. M. (2006). Lifespan Cognition: Mechanisms of Change. Oxford: Oxford University Press.

Boot, W. R., Champion, M., Blakely, D. P., Wright, T., Souders, D. J., and Charness, N. (2013). Video games as a means to reduce age-related cognitive decline: attitudes, compliance, and effectiveness. Front. Psychol. 4:31. doi: 10.3389/fpsyg.00031

Boot, W. R., Kramer, A. F., Simons, D. J., Fabiani, M., and Gratton, G. (2008). The effects of video game playing on attention, memory, and executive control. Acta Psychol. 129, 387-398. doi: 10.1016/j.actpsy.2008.09.005

Brookmeyer, R., Evans, D. A., Hebert, L., Langa, K. M., Heeringa, S. G., Plassman, B. L., et al. (2011). National estimates of the prevalence of Alzheimer's disease in the United States. Alzheimer Dement. 7, 61-73. doi: 10.1016/j.jalz.2010.11.007

Buitenweg, J. I. V., Murre, J. M. J., and Ridderinkhof, K. R. (2012). Brain training in progress: a review of trainability in healthy seniors. Front. Hum. Neurosci. 6:183. doi: 10.3389/fnhum.2012.00183

Cacciopo, J. T., Hughes, M. E., Waite, L. J., Hawkley, L. C., and Thisted, R. A. (2006). Loneliness as a specific risk factor for depressive symptoms: cross-sectional and longitudinal analyses. Psychol. Aging 21, 140-151. doi: 10.1037/08827974.21.1.140

Cain, M. S., Landau, A. N., and Shimamura, A. P. (2012). Action video game experience reduces the cost of switching tasks. Atten. Percept. Psychophys. 74, 641-647. doi: 10.3758/s13414-012-0284-1

Cassavaugh, N. D., and Kramer, A. F. (2009). Transfer of computer based training to simulated driving in older adults. Appl. Ergon. 40, 943-952. doi: 10.1016/j.apergo.2009.02.001

Chen, C., and Tonegawa, S. (1997). Molecular genetic analysis of synaptic plasticity, activity-dependent neural development, learning, and 
memory in the mammalian brain. Annu. Rev. Neurosci. 20, 157-184. doi: 10.1146/annurev.neuro.20.1.157

Chisholm, J. D., and Kingstone, A. (2012). Improved top-down control reduces oculomotor capture: the case of action video game players. Atten. Percept. Psychophys. 74, 257-262. doi: 10.3758/s13414-011-0253-0

Clark, J. E., Lamphear, A. K., and Riddick, C. C. (1987). The effects of videogame playing on the response selection processing of elderly adults. J. Gerontol. 42, 82-85.

Colcombe, S. J., Kramer, A. F., Erickson, K. I., Scalf, P., McAuley, E., Cohen, N., et al. (2004). Cardio-vascular fitness, cortical plasticity, and aging. Proc. Natl. Acad. Sci. U.S.A. 101, 3316-3321. doi: 10.1073/pnas.040026610

Colcombe, S., and Kramer, A. F. (2003). Fitness effects on the cognitive function of older adults A meta-analytic study. Psychol. Sci. 14, 125-130. doi: 10.1111/14679280.t01-1-01430

Colzato, L. S., Van Leeuwen, P. J. A., Van Den Wildenberg, W. P. M., and Hommel, B. (2010). DOOM'd Switch: superior cognitive flexibility in players of first person shooter games. Front. Psychol. 1:8. doi: 10.3389/fpsyg.2010.00008

Craik, F. I. M., and Bialystok, E. (2006). Cognition through the lifespan: mechanisms of change. Trends Cogn. Sci. 10, 131-139. doi: 10.1016/j.tics.2006. 01.007

Craik, F. I. M., Winocur, G., Palmer, H., Binns, M. A., Edwards, M., Bridges, K., et al. (2007). Cognitive rehabilitation in the elderly: effects on memory. J. Int. Neuropsych. Soc. 13, 132-142. doi: 10.1016/j.tics.2006.01.007

Dahlin, E., Nyberg, L., Bäckman, L., and Neely, A. S. (2008). Plasticity of executive functioning in young and older adults: immediate training gains, transfer, and long-term maintenance. Psycholog. Aging 23, 720-730. doi: 10.1037/ a0014296

Drew, D., and Waters, J. (1986). Video games: utilization of a novel strategy to improve perceptual motor skills and cognitive functioning in the noninstitutionalized elderly. Cogn. Rehabil. 4, 26-31.

Eckert, M. A. (2011). Slowing down: age-related neurobiological predictors of processing speed. Front. Neurosci. 5:25. doi: 10.3389/fnins.2011.00025

Edwards, J. D., Wadley, V. G., Vance, D. E., Wood, K., Roenker, D. L., and Ball, K. K. (2005). The impact of speed of processing training on cognitive and everyday performance. Aging Ment. Health 9, 262-271. doi: 10.1080/13607860412331336788

Erickson, K. I., Colcombe, S. J., Wadhwa, R., Bherer, L., Peterson, M. S., Scalf, P. E., et al. (2007). Training- induced plasticity in older adults: effects of training on hemispheric asymmetry. Neurobiol. Aging 28, 272-283. doi: 10.1016/j.neurobiolaging.2005.12.012

Feng, J., Spence, I., and Pratt, J. (2007). Playing an action video game reduces gender differences in spatial cognition. Psychol. Sci. 18, 850-855. doi: 10.1111/j.1467-9280.2007.01990.x

Ferri, C. P., Prince, M., Brayne, C., Brodaty, H., Fratiglioni, L., Ganguli, M., et al. (2005). Global prevalence of dementia: a Delphi consensus study. Lancet 366, 2112-2117. doi: 10.1016/S0140-6736(05)67889-0

Folstein, M. F., Folstein, S. E., and McHugh, P. R. (1975). Mini-mental state. A practical method for grading the cognitive state of patients for the clinician. J. Psychiat. Res. 12, 189-1998.

Green, C. S., and Bavelier, D. (2003). Action video game modifies visual selective attention. Nature 423, 534-537. doi: 10.1038/nature01647

Green, C. S., and Bavelier, D. (2006). Effects of action video game playing on the spatial distribution of visual selective attention. J. Exp. Psychol. Hum. 32, 1465-1478. doi: 10.1037/0096-1523.32.6.1465

Green, C. S., Li, R., and Bavelier, D. (2010). Perceptual learning during action video game playing. Top. Cogn. Sci. 2, 201-216. doi: 10.1111/j.1756-8765.2009. 01054.x

Gunning-Dixon, F. M., and Raz, N. (2003). Neuroanatomical correlates of selected executive functions in middle-aged and older adults: a prospective MRI study. Neuropsychologia 41, 1929-1941. doi: 10.1016/S0028-3932(03)00129-5

Hampstead, B. M., Shatian, K., Phillips, P. A., Amaraneni, A., Delaune, W. R., and Stringer, A. Y. (2012). Mnemonic strategy training improves memory for object location associations in both healthy elderly and patients with amnestic mild cognitive impairment: a randomized, single-blind study. Neuropsychology 26, 385-399. doi: 10.1037/a0027545

Hasher, L., Zacks, R., and May, C. (1999). Inhibitory control, circadian arousal and age. Atten. Perform. 17, 653-677.

Heaton, R. K. (1981). A Manual for the Wisconsin Card Sorting Test. Odessa, FL: Western Psychological Services.
Hedden, T., and Gabrieli, J. D. E. (2004). Insights into the ageing mind: a view from cognitive neuroscience. Nat. Rev. Neurosci. 5, 87-96. doi: 10.1038/nrn1323

Hertzog, C., Kramer, A. F., Wilson, R. S., and Lindenberger, U. (2009). Enrichment effects on adult cognitive development. Psychol. Sci. Public Interest 9, 1-65. doi: 10.1111/j.1539-6053.2009.01034.x

Holtmaat, A., and Svoboda, K. (2009). Experience-dependent structural synaptic plasticity in the mammalian brain. Nat. Rev. Neurosci. 10, 647-658. doi: $10.1038 / \mathrm{nrn} 2699$

Hötting, K., and Röder, B. (2013). Beneficial effects of physical exercise on neuroplasticity and cognition. Neurosci. Biobehav. Rev. 37(9 Pt B), 2243-2257. doi: 10.1016/j.neubiorev.2013.04.005

Hoyer, W. J., and Verhaeghen, P. (2006). "Memory aging," in Handbook of the psychology of Aging, eds J. Birren and W. Schaie (Burlington, MA: Elsevier Academic Press), 209-232.

Jones, S., Nyberg, L., Sandblom, J., Stigsdotter Neely, A., Ingvar, M., Petersson, K. M., et al. (2006). Cognitive and neural plasticity in aging: general and task specific limitations. Neurosci. Biobehav. Rev. 30, 864-871. doi: 10.1016/j.neubiorev.2006.06.012

Kempermann, G., Gast, D., and Gage, F. H. (2002). Neuroplasticity in old age: sustained five-fold induction of hippocampal neurogenesis by long-term environment enrichment. Ann. Neurol. 52, 135-143. doi: 10.1002/ana.10262

Kempermann, G., Wiskott, L., and Gage, F. H. (2004). Functional significance of adult neurogenesis. Curr. Opin. Neurobiol. 14, 186-191. doi: 10.1016/j.conb.2004.03.001

Knaepen, K., Goekint, M., Heyman, E. M., and Meeusen, R. (2010). Neuroplasticity - Exercise-induced response to peripheral brain-derived neurotrophic factor. Sports Med. 40, 765-801. doi: 10.2165/11534530

Kray, J., and Lindenberger, U. (2000). Adult age differences in task switching. Psychol. Aging 15, 126. doi: 10.1037//0882-7974.15.1.126

Kueider, A. M., Parisi, J. M., Gross, A. L., and Rebok, G. W. (2012). Computerized cognitive training with older adults: a systematic review. PLoS ONE 7:e40588. doi: 10.1371/journal.pone.0040588

Lee, H., Boot, W. R., Basack, C., Voss, M. W., Prakash, R. S., Neider, M., et al. (2012). Performance gains from directed training do not transfer to untrained tasks. Acta Psychol. 139, 146-158. doi: 10.1016/j.actpsy.2011.11.003

Lee, S.-C., Schmiedek, F., Huxhold, O., Röcke, C., Smith, J., and Lindenberger, U. (2008). Working memory plasticity in old age: practice gain, transfer, and maintenance. Psychol. Aging 23, 731-742. doi: 10.1037/a0014343

Li, S.-C., Brehmer, Y., Shing, Y. L., Werkle-Bergner, M., and Lindenberger, U. (2006). Neuromodulation of associative and organizational plasticity across the life span: empirical evidence and neurocomputational modeling. Neurosci. Biobehav. Rev. 30, 775-790. doi: 10.1016/j.neubiorev.2006.06.004

Lindenberger, U., Li, S.-C., and Bäckman, L. (2006). Methodological and conceptual advances in the study of brain-behavior dynamics: a multivariate lifespan perspective. Neurosci. Biobehav. Rev. 30, 713-717. doi: 10.1016/j.neubiorev.2006.06.006

Lövdén, M., Lindenberger, U., Bäckman, L., Schaefer, S., and Schmiedek, F. (2010). A theoretical framework for the study of adult cognitive plasticity. Psychol. Bull. 136, 659-676. doi: 10.1037/a0020080

Lustig, C., Shah, P., Seidler, R., and Reuter-Lorenz, P. A. (2009). Aging, training, and the brain: a review and future directions. Neuropsychol. Rev. 19, 504-522. doi: 10.1007/s11065-009-9119-9

Mahncke, H. W., Connor, B. B., Appelman, J., Ahsanuddin, O. N., Hardy, J. L., Wood, R. A., et al. (2006). Memory enhancement in healthy older adults using a brain plasticity-based training program: a randomized, controlled study. Proc. Natl. Acad. Sci. U.S.A. 103, 12523-12528. doi: 10.1073/pnas.0605194103

Maillot, P., Perrot, A., and Hartley, A. (2012). Effects of interactive physical-activity videogame training on physical and cognitive function in older adults. Psychol. Aging 27, 289-600. doi: 10.1037/a0026268

Martínez, J., Onís, M. C., Dueñas, H., Aguado, C., Colomer, C., and Luque, R. (2002). The Spanish version of the Yesavage Abbreviated Questionnaire (GDS) to screen depressive dysfunctions in patients older than 65 years. Medifam 12, 620-630. doi: 10.4321/S1131-57682002001000003

Mayas, J., Parmentier, F. B. R., Andrés, P., and Ballesteros, S. (2014). Plasticity of attentional functions in older adults after non-action video game training. PLoS ONE 9:e92269. doi: 10.1371/journal.pone.0092269

McDougall, S., and House, B. (2012). Brain training in older adults: evidence of transfer to memory span performance and pseudo-Matthew effects. Aging Neuropsychol. Cogn. 19, 195-221. doi: 10.1080/13825585.2011.640656 
McKay, S. M., and Maki, B. E. (2010). Attitudes of older adults toward shooter games: an initial study to select an acceptable game for training visual processing. Gerontechnology 9, 5-17. doi: 10.4017/gt.2010.09. 01.001 .00

Melby-Lervåg, M., and Hulme, C. (2013). Is working memory training effective? A meta-analytic review. Dev. Psychol. 49, 270-291. doi: 10.1037/ a0028228

Milner, B. (1963). Effects of different brain lesion on card sorting. Arch. Neurol. 9, $100-110$.

Milner, B. (1971). Interhemispheric differences in the localization of psychological processes in man. Br. Med. Bull. 27, 272-277. doi: 10.1001/archneur.1963.00460070100010

Mitchell, D. B., and Bruss, P. J. (2003). Age differences in implicit memory: conceptual, perceptual o methodological. Psychol. Aging 18, 807-822. doi: 10.1037/0882-7974.18.4.807

Miyake, A., Friedman, N. P., Emerson, M. J., Witzki, A. H., Howerter, A., and Wagner, R. D. (2000). The unity and diversity of executive functions and their contributions to complex "frontal lobe" tasks: a latent variable analysis. Cogn. Psychol. 41, 49-100. doi: 10.1006/cogp.1999.0734

Mozolic, J. L., Long, A. B., Morgan, A. R., Rawley-Payne, M., and Laurienti, P. J. (2011). A cognitive training intervention improves modality-specific attention in a randomized controlled trial of healthy older adults. Neurobiol. Aging 32, 655-668. doi: 10.1016/j.neurobiolaging.2009.04.013

Nap, H. H., de Kort, Y. A. W., and Ijselsteijn, W. A. (2009). Senior gamers: preferences, motivations and needs. Gerontechnology 8, 247-262. doi: 10.4017/gt.2009.08.04.003.00

Nieboer, A., Lindenberg, S., Boomsma, A., and Bruggen, A. C. V. (2005). Dimensions of wellbeing and their measurement: the SPF-IL scale. Soc. Indic. Res. 73, 313-353. doi: 10.1007/s11205-004-0988-2

Nilsson, L. G. (2003). Memory function in normal aging. Acta Neurol. Scand. 107, 7-13. doi: 10.1034/j.1600-0404.107.s179.5.x

Nouchi, R., Taki, Y., Takeuchi, H., Hashizume, H., Akitsuki, Y., Shigemune, Y., et al. (2012). Brain training game improves executive functions and processing Speed in the elderly: a randomized controlled trial. PLOS ONE 7:e29676. doi: 10.1371/journal.pone.0029676

Oei, A. C., and Petterson, M. D. (2013). Enhancing cognition with video games: a multiple game training study. PLoS ONE 8:e58546. doi: 10.1371/journal.pone.0058546

Osorio, A., Pouthas, V., Fay, S., and Ballesteros, S. (2010). Ageing affects brain activity in highly educated older adults: an ERP study using a word-stem priming task. Cortex 46, 522-534. doi: 10.1016/j.cortex.2009.09.003

Owen, A. M., Hampshire, A., Grahn, J. A., Stenton, R., Dajani, S., Burns, A. S., et al. (2010). Putting brain training to test. Nat. Lett. 465, 775-778. doi: 10.1038/nature09042

Park, D. C., and Bischof, G. N. (2013). The aging mind: neuroplasticity in response to cognitive training. Dialogues Clin. Neurosci. 15, 109-119.

Park, D. C., Davidson, L., Lautenschlager, G., Smith, A. D., Smith, P., and Hedden, T. (2002). Models of visuo-spatial and verbal memory across the adult lifespan. Psychol. Aging 17, 299-320. doi: 10.1037/0882-7974.17.2.299

Park, D. C., and Gutchess, A. H. (2002). Aging, cognition, and culture: a neuroscientific perspective. Neurosci. Biobehav. Rev. 26, 859-867. doi: 10.1016/S01497634(02)00072-6

Park, D. C., and Reuter-Lorenz, P. A. (2009). The adaptive brain: ageing and neurocognitive scaffolding. Annu. Rev. Psychol. 60, 173-196. doi: 10.1146/annurev.psych.59.103006.093656

Pascual-Leone, A., Amedi, A., Fregni, F., and Merabet, L. B. (2005). The plastic human brain cortex. Annu. Rev. Psychol. 28, 377-401. doi: 10.1146/annurev.neuro.27.070203.144216

Peter, C., Kreisner, A., Schröter, M., Hyosun, K., Bieber, G., Öhberg, F., and Ballesteros, S. (2013). AGNES: connecting people in a multimodal way. J. Multimod. User Interf. 7, 229-245. doi: 10.1007/s12193-013-0118-z

Powers, K. L., Brooks, P. J., Aldrich, N. J., Palladino, M., and Alfieri, L. (2013). Effects of video-game play on information processing: a metaanalytic investigation. Psychon. Bull. Rev. 20, 1055-1079. doi: 103758/s134230418-z

Raz, N. (2000). "Aging of the brain and its impact on cognitive performance: integration of structural and functional findings," in The Handbook of Aging and Cognition, eds F. I. M. Craik and T. A. Salthouse (Mahwah, NJ: Lawrence Erlbaum Associates), 1-90.
Raz, N., Lindenberger, U., Rodrigue, K. M., Kennedy, K. M., Head, D., Williamson, A., et al. (2005). Regional brain changes in aging healthy adults: general trends, individual differences and modifiers. Cereb. Cortex 15, 1676-1689. doi: 10.1093/cercor/bhi044

Reddick, T. S., Shipstead, Z., Fried, D. E., Hambrick, D. Z., Kane, M. J., and Engle, R. W. (2013). No evidence of intelligence improvement after working memory training: a randomized, placebo-controlled study. J. Exp. Psychol. Gen. 142, 359-379. doi: 10.1037/a0029082

Reitz, C., Brayne, C., and Mayeux, R. (2011). Epidemiology of Alzheimer disease. Nat. Rev. Neurol. 7, 137-152. doi: 10.1038/nrneurol.2011.2

Rey, A. (1942). L'examen psychologique dans les cas d'encéfalopathie traumatique. Arch. Psychol. 28, 286-340.

Rey, A. (1999). Test de Copia y de Reproducción de Memoria de una Figura Geométrica Compleja (Manual). Madrid: TEA Ediciones.

Richardson, J. T. E., and Vecchi, T. (2002). A jigsaw-puzzle imagery task for assessing active visuospatial processes in old and young people. Behav. Res. Meth. Ins. Cogn. 34, 69-82. doi: 10.3758/BF03195425

Rönnlund, M., Nyberg, L., Bäckman, L., and Nilsson, L.-G. (2005). Stability, growth and decline in adult life span development of declarative memory: crosssectional and longitudinal data from a population-based study. Psychol. Aging 20, 3-18. 10.1037/0882-7974.20.1.3

Salthouse, T. A. (1996). The processing-speed theory of adult age differences in cognition. Psychol. Rev. 103, 403-428. doi: 10.1037//0033-295X. 103.3.403

Salthouse, T. A., and Ferrer-Caja, E. (2003). What needs to be explained to account for age-related effects on multiple cognitive variables? Psychol. Aging 18, 91-110. doi: 10.1037/0882-7974.18.1.91

Sebastián, M., and Ballesteros, S. (2012). Effects of normal aging on eventrelated potentials and oscillatory brain activity during a haptic repetition priming task. Neuroimage 60, 7-20. doi: 10.1016/j.neuroimage.2011. 11.060

Shipstead, Z., Redick, T. S., and Engle, R. W. (2012). Is working memory training effective? Psychol. Bull. 138, 628-654. doi: 10.1037/a0027473

Smith, G. E., Housen, P., Yaffe, K., Ruff, R., Kennison, R. F., Mahncke, H. W., et al. (2009). A cognitive training program based on principles of brain plasticity: results from the improvement in memory with plasticity-based adaptive cognitive training (IMPACT) study. J. Am. Geriatr. Soc. 57, 594-603. doi: 10.1111/j.1532-5415.2008.02167.x

Snodgrass, J. G., and Vanderwart, M. (1980). A standardized set of 260 pictures: norms for name agreement, image agreement, familiarity and visual complexity. J. Exp. Psychol. Hum. Learn. 6, 174-215. doi: 10.1037//0278-7393.6. 2.174

Squire, L. R., Stark, C. E., and Clark, R. E. (2004). The medial temporal lobe. Annu. Rev. Neurosci. 27, 279-306. doi: 10.1146/annurev.neuro.27.070203. 144130

Stemberg, D. A., Ballard, K., Hardy, J. L., Katz, B., Doraiswamy, P. M., and Scanlon, M. (2013). The largest human cognitive performance dataset reveals insights into the effects of lifestyle factors and aging. Front. Hum. Neurosci. 7:292. doi: 10.3389/fnhum.2013.00292

Thompson, G., and Foth, F. (2005). Cognitive-training programs for older adults: what are they and can they enhance mental fitness? Educ. Gerontol. 31, 603-626. doi: 10.1080/03601270591003364

Toril, P., Reales, J. M., and Ballesteros, S. (2014). Video game training enhances cognition of older adults? A meta-analytic study. Psychol. Aging 29, 706-716. doi: $10.1037 / \mathrm{a} 0037507$

Valenzuela, M., and Sachdev, P. (2009). Can cognitive exercise prevent the onset of dementia? Systematic review of randomized clinical trials with longitudinal follow-up. Am. J. Geriat. Psychiat. 17, 179-187. doi: 10.1097/JGP.0b013e3181953b57

Waterworth, J. A., Ballesteros, S., and Peter, C. (2009). "User-sensitive home-based systems for successful ageing," in Human System Interactions (HSI'09) (Catania: IEEE Computer Society), 542-545. doi: 10.1109/HSI.2009.5091036

Wechsler, D. (1997). Wechsler Memory Scale (WMS-III). San Antonio, TX: Psychological Corporation and Harcourt Brace.

Wechsler, D. (1999). WAIS-III: Wechsler Adult Intelligence Scale, Administration and Scoring Manual, 3rd Edn. San Antonio, TX: Psychological Corporation and Harcourt Brace.

Wechsler, D., and Pereña, J. (2004). WMS-III: Escala de Memoria de Wechsler-III. Madrid: Tea. 
West, R. (1996). An application of the prefrontal cortex function theory to cognitive aging. Psychol. Bull. 120, 272-292.

Wiggs, C. L., Weisberg, J., and Martin, A. (2006). Repetition priming across the adult lifespan — the long and short of it. Aging Neuropsychol. Cogn. 13, 308-325. doi: 10.1080/138255890968718

Willis, S. L., Tennstedt, S. L., Marsiske, M., Ball, K., Elias, J., Koepke, K. M. et al. (2006). Long-term effects of cognitive training on everyday functional outcomes in older adults. JAMA 296, 2805-2814. doi: 10.1001/jama.296.23.2805

Wolinsky, F. D., Vander Weg, M. W., Howren, M. B., Jonas, M. P., and Dotson, M. D. (2013). A randomized controlled trial of cognitive training using a visual speed of processing intervention in middle aged and older adults. PLoS ONE 8:e61624. doi: 10.137/journal.pone.0061624

Yesavage, J. A., Brink, T. L., Rose, T. L., Lum, O., Huang, V., Adey, M., et al. (1983). Development and validation of a geriatric depression screening scale: a preliminary report. J. Psychiat. Res. 17, 37-49.

Zimprich, D. M. (2002). Can longitudinal change in processing speed explain longitudinal changes in fluid intelligence? Psychol. Aging 17, 690-695. doi: 10.1037//0882-7974.17.4.690
Conflict of Interest Statement: The authors declare that the research was conducted in the absence of any commercial or financial relationships that could be construed as a potential conflict of interest.

Received: 19 December 2013; paper pending published: 12 January 2014; accepted: 24 September 2014; published online: 14 October 2014.

Citation: Ballesteros S, Prieto A, Mayas J, Toril P, Pita C, Ponce de León L, Reales JM and Waterworth J (2014) Brain training with non-action video games enhances aspects of cognition in older adults: a randomized controlled trial. Front. Aging Neurosci. 6:277. doi: 10.3389/fnagi.2014.00277

This article was submitted to the journal Frontiers in Aging Neuroscience.

Copyright (c) 2014 Ballesteros, Prieto, Mayas, Toril, Pita, Ponce de León, Reales and Waterworth. This is an open-access article distributed under the terms of the Creative Commons Attribution License (CC BY). The use, distribution or reproduction in other forums is permitted, provided the original author(s) or licensor are credited and that the original publication in this journal is cited, in accordance with accepted academic practice. No use, distribution or reproduction is permitted which does not comply with these terms. 